\title{
Insights into the Category of Gender (with special reference to gender-marking avoidance strategies)
}

\author{
Lili Karapetyan, Lusine Danukhyan \\ Yerevan State University
}

\begin{abstract}
Gender is an issue that has long preoccupied linguists, and the category of gender is one of the still unsolved puzzles of linguistic science. There has never been a complete agreement between scientists with regard to gender origin, nor there is unanimity of opinion as to its function in different language systems and, in general, to its definition. The present study focuses on the origin and historical development of the category of gender, classification of languages according to gender types, the peculiarities of gendered and genderless languages, gender-marking avoidance strategies. Through the comparative method of analysis English and Armenian gender systems are compared with an aim to reveal the similarities and differences in terms of functions, gender indicators in proverbs, as well as types of reference.
\end{abstract}

Key words: category of gender, gender systems, gendered and genderless languages, gender-marking avoidance strategies.

\section{Introduction}

The word gender has been used since the $14^{\text {th }}$ century as a grammatical term, referring to classes of noun as masculine, feminine, or neuter groups. Grammatical gender is a formal category, but it does not refer to the biological difference between man and woman; rather it is an integral part of the linguistic system and it also includes inanimate entities. This system is used in approximately one quarter of the world's languages. In 257 languages from different geographical areas and linguistic families, 112 are shown to have a gender system (Oxford Research Encyclopedia). 
In linguistics grammatical gender is a specific form of noun class system in which the division of noun classes forms an agreement system with another aspect of the language, such as adjectives, articles, pronouns, or verbs. This system is used in approximately one quarter of the world's languages. In these languages, most or all nouns carry one value of the grammatical category called gender, the values present in a given language (of which there are usually two or three) are called the genders of that language (Gender, Wikipedia). Gender category is observed in such old languages as Sanskrit, Latin, Ancient Greek, Old Persian, Ancient Egyptian, etc.

According to the definition given in Oxford Online Dictionary (2019) gender is any class (typically masculine, feminine, common, neuter) of nouns and pronouns distinguished by the different inflections which they have and which they require in words syntactically associated with them. Grammatical gender is only very loosely associated with natural distinctions of "sex".

The gender category cannot be perceived and comprehended unless we reveal certain notions such as gender types, classification of languages according to the mentioned types, the origin of the category of gender and its historical development, the peculiarities of gendered and genderless languages, gendermarking avoidance strategies, and some others.

\section{Gender Origin and Classification of Languages}

\section{According to Gender Types}

The origin of the grammatical category of gender in different languages is connected with the outlook and world view of ancient people. At the initial stages of world discovery people divided the inanimate objective reality according to fertility, movement and growth. The objects that give some kind of products, grow (up) or move from their initial position were considered to be feminine (earth, tree, water, sun, moon, etc.) and those that do not correspond to these criteria were considered masculine (Aghayan 2010:187). In the languages where the grammatical category of gender is better demonstrated, the difference is better seen, e.g. in Russian - вода (f), луна (f), земля (f) and камень (m), in Spanish - la tierra (f), una flor (f), el agua (f), etc. 
Some languages do not have distinctions of the grammatical category of gender: these languages are called genderless. They lack gender-specific words, prefixes or suffixes. The Armenian language belongs to this group. According to the gender type, languages are divided into 5 groups - those that have:

- Masculine and Feminine - French, Hindi, Irish, Spanish, etc;

- Common and Neuter - Danish, Norwegian, Swedish, Dutch;

- Animate and Inanimate - Georgian, Sumerian, Elamite, etc;

- Masculine, Feminine and Neuter - Latin, Old English, Russian, etc;

- More than three genders - Polish, Czech, Bantu languages, etc. (List of Languages by Type of Grammatical Genders, Wikipedia).

According to J. Lyons (1968:283), gender "plays a relatively minor part in the grammar of English by comparison with its role in many other languages." Following Aristotle's model, J. Harris (in Teterin 2012) stated that modern English has a "natural" or "logical" system of gender. This is neither a grammatical category, nor a lexical one, but semantic, based largely on biological sex differences, and, therefore, sensible only for human and animal reference. Thus, all nouns referring to females are logically or naturally assumed to be feminine in gender (she). Nouns referring to male beings or creatures are naturally assumed to have male reference (he); and everything else (animals, plants, objects, abstract qualities, etc.) is assumed to be unmarked for gender (it).

Ilyish (in Tiv'jaeva 2012:4) states that not a single word in Modern English shows morphological meaning of gender. Thus, the word sister and brother do not show any difference in their morphological forms, but only in lexical meanings. Consequently, the difference between actor and actress is purely lexical. In other words, the category of gender should not be confused with the category of sex, as the latter is an objective biological category.

While some nouns in the English language can only have one type of reference, others are double-gender or multiple-gender nouns:

1. Masculine only: for male human beings (father, boy, king).

2. Feminine only: for female human beings (mother, girl, queen).

3. Neuter only: inanimate (non-sexed) objects (book, tree, room). 
4. Masculine or feminine: male or female human beings. These have been described as "common gender", or "dual gender", and usually are nouns in -er (driver, employer, singer), -ian (vegetarian), or -ist (loyalist, artist, typist).

5. Masculine or neuter: male animals (billy-goat, ram, bull, drake, boar, cock), and personifications of certain objects of the human physical or mental universe (sun, river, summer, winter, love, death, time, war).

6. Masculine, feminine or neuter: animate beings whose sex is indeterminate (baby, infant, child, cat, dog). This is often the case of young children or lower animals (fish, birds, reptiles, insects, etc.) (Teterin 2012:160).

In Old English, all nouns were treated as either masculine, or feminine or neuter, this system fell out of use during the Middle English period. In Modern English the category of gender is mostly distinguished by personal pronouns (third person, singular): he-masculine, she - feminine, it - neuter. There are some other indicators:

$\checkmark$ Certain words acting as sex-indicators: girl-friend, boy-friend, Tomcat, Jane-cat, billy-goat, nanny-goat, policewoman,

$\checkmark$ Bound morphemes indicating feminine gender: actress, tigress, heroine,

$\checkmark$ Different words used for indicating the gender: lady, queen, king, uncle, aunt.

Modern Armenian, which is considered to be a genderless language, has similarities with English in terms of giving a gender to its gender-neutral vocabulary:

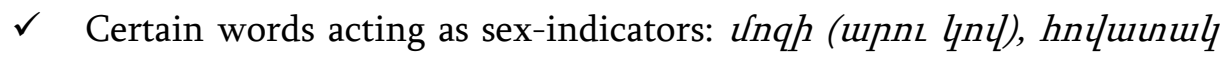
(upnz dh), etc.

$\checkmark$ Suffix - nzhh indicating feminine gender of the nouns: uzulqtpunnzhh, pd2lnzhh, qnpouцupnzh $\boldsymbol{h}$, etc.

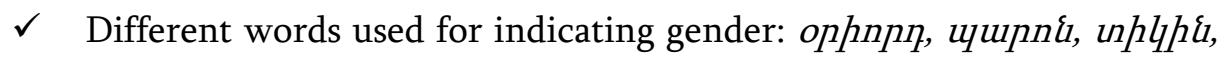
plinh, pnujp, etc.

In the English language the $3^{\text {rd }}$ person singular personal pronouns distinguish the genders, consequently, there are three pronouns he (for masculine), she (for feminine) and it (for neuter). Though nowadays in the 
Armenian language the equivalent of he/she is gender-neutral \&uw, in Western Armenian the $3^{\text {rd }}$ person singular pronoun once had two genders $\varepsilon_{i}(\mathrm{f})$ and $\varepsilon u u$ (m) (Aghayan 1976:1018).

In the English language animals are referred to as nouns of neuter gender even when their sex is known to the speaker:

The elephant slowly lifted its trunk.

The cat was licking its body.

My cat is celebrating his $5^{\text {th }}$ birthday today.

Peter's puppy is so sweet: she jumps on me every time

I call on them.

Sometimes the choice of the gender is made by the author/speaker as it includes an emotional component, too:

Titanic, Giant White Star Liner Sinks After Collision

With Iceberg on Her Maiden Voyage.

Do you like my new car, isn't she beautiful?

But when used in a purely geographical sense the gender choice of inanimate things or places may be referred to as it (Mkhitaryan et al 2001:18):

New York City is the most populous city in the USA, its population reaches 8538 million.

Paris is the capital of France. It is considered to be the city of love.

In fiction these nouns get their gender according to the context and the author's taste:

New York City is the most fatally fascinating thing in America. She sits like a great witch at the gate of the country.

(Johnson 2004:51) 
I shall attempt no such supergatory task as a description of Paris. It impressed me as a perfect and perfectly beautiful city.

(Johnson 2004:72)

Paris was a universe whole and entire unto herself, hollowed and fashioned by history; so she seemed in this age of Napoleon III with her towering buildings, her massive cathedrals....

(Rice 1976:67)

\section{Gender Markers in English and Armenian Proverbs}

Being a purely linguistic category gender reveals a lot about human mind which is better seen when observing the wise truths handed from generation to generation as in the case of proverbs (the examples are taken from English Proverbs and Sayings, 1987). When studying English proverbs one may see the tendency of using the word man as the subject in most of them. This phenomenon is conditioned by the fact that for many centuries men have been the breadwinners and decision makers of the family and have been focused on:

No man is an island.

$A$ man is the only animal that can be skinned more than once.

A man who marries twice is a two-time loser.

$A$ man is known by his friends.

The word man is a proper indicator of masculine gender, but in the proverbs above it may also mean a human being in general. Yet, one cannot be certain what gender the proverb demonstrates or whether it wants to have a stress on gender or not.

Other proverbs already solve this kind of puzzles directly pointing to the gender by its meaning or a suitable pronoun: 
Marry a handsome man and you marry trouble.

The smart man knows how little he really knows.

Behind every great man there's a great woman.

The words humanity, human race, person, people can be acceptable substitutions to avoid sexist language in some cases, though it changes the agesold wisdom to some degree:

$A$ dog is a man's best friend $=>A$ dog is human's best friend.

$A$ good man is hard to find. => Good people are hard to find.

$A$ man is known by his friends. => People are known by their

friends.

Clothes make the man. => Clothes make identity.

Being a gender neutral language, Armenian avoids this kind of misunderstandings even in similar proverbs. In Armenian translation the word uupn stands for the word man. Generally, the word refers to masculine gender, but without a clear indicator one may understand as they wish:

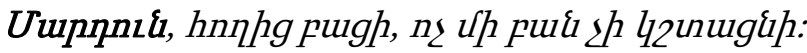

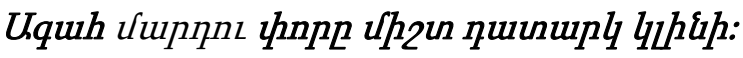

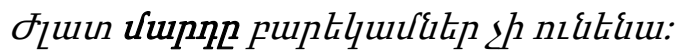

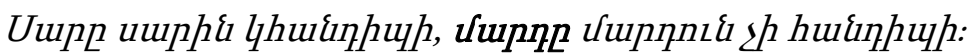

Just like in English, in the Armenian language sometimes there is serene indicator:

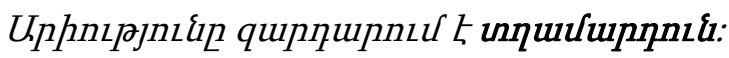

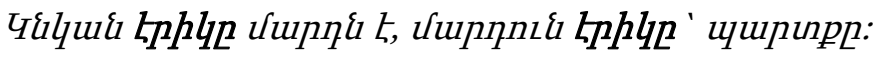

In the Armenian language there is another good way for avoiding gender indication - the use of substantivized adjectives: 


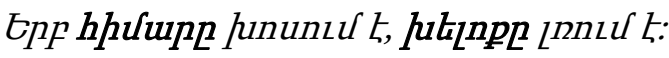

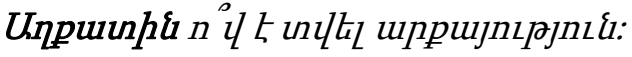

\section{Gender-Marking Avoidance Strategies}

Sometimes in formal communication one faces different problems connected with sexist languages. When using cautious language people need some tips how to use appropriate pronouns or words. For example, in Spanish, Italian and other sexist languages when referring to a group of people it is grammatically correct to use masculine gender if there is at least one male representative. Only when the whole group consists of females the speakers use feminine gender e.g. Las chicas comen en un café Italiano. This sentence assumes that all the members of the group are female, while without a certain context one can never guess if the group members of the sentence Los chicos comen en un café Italiano are all male or there are representatives from both genders.

The English language speakers do not come up to this kind of misunderstanding, but they find themselves in other sorts of tricky situations. In the English language gender based errors are connected either with the $3^{\text {rd }}$ person singular pronouns or with profession indicating nouns. Pronoun-related form of sexist writing occurs in a sentence such as:

When a student goes to university, he should understand the importance of higher education.

Such a sentence assumes that all the students are male. In a cautious language the speaker could use:

$\checkmark$ he or she or s/he or he/she instead of he, i.e. When a student goes to university, he/she should understand the importance of higher education.

$\checkmark$ one instead of he, i.e. When a student goes to university, one should understand the importance of higher education.

$\checkmark$ Another way of avoiding the sexist pronoun is to use they instead of he, i.e. When a student goes to university, they should understand the importance of higher education. 
$\checkmark$ On the other hand, the speaker may not only change the pronoun but the number of the noun in the main phrase making it plural, i.e. When students go to university, they should understand the importance of higher education.

$\checkmark$ Another solution is to avoid using gender pronouns and use nouns or neuter pronouns instead: Ask him to be impartial. - Ask your teacher to be impartial.

When a teacher is motivating, his students will be more interested in studying the subject. - When you are motivating, your students will be more interested in studying the subject.

When a teacher is motivating, his students will be more interested in studying the subject. - When we teachers motivate, our students will be more interested in studying the subject.

The complex diversity of linguistic units enables speakers/users to come up with avoiding structures even for already defined sexist avoidance techniques.

Once the doctor is ready to operate, he or she must wash his or her hands. - When ready to operate, doctors must wash their hands.

$\checkmark \quad$ In the case of an inanimate object the use of indefinite article is also recommended. In different structures and contexts one may use the indefinite article to avoid gender based judgements, e.g.

Who has left a book at cafeteria?

Someone dropped a purse in the street.

As mentioned above, the second use of sexist language is connected with nouns such as businessman, fireman, chairman, etc. Nowadays, with the growth of awareness in the society women have started to occupy positions which were meant for men only in the previous centuries. In order not to hurt their feelings or worsen relationship with them one may find alternatives to some position names:

chairman $=>$ presiding officer

businessman $=>$ business executive

congressman $=>$ congressional representative 


$$
\begin{aligned}
& \text { fireman }=>\text { firefighter } \\
& \text { stewardess }=>\text { flight attendant }
\end{aligned}
$$

\section{Conclusion}

Being a linguistic category, gender reveals a lot about human mind, which is unconditionally reflected in the language. While awareness grows in the society, there is a growing need for some tips and strategies to avoid problems connected with sexist languages. Nowadays the flexibility of a language and the complex diversity of linguistic units enable speakers/users to come up with sexist avoidance techniques, i.e. avoid the use of gender displaying words and use neutral words and phrases instead to encourage equality and be linguistically polite by using cautious language.

\section{References:}

1. Aghayan, E. (2010) Lezvabanutyan neratsutyun. Yerevan: YSU.

2. Aghayan, E. (1976) Ardi hayereni batsatrakan bararan. Yerevan: Hayastan.

3. Lyons, J. (1968) Introduction to Theoretical Linguistics. Cambridge: CUP.

4. Mkhitaryan, Ye.; Hambartsoumyan, N.; Markaryan, A.; Avakyan, N. (2001) A Basic English Grammar, Morphology. Yerevan: Zangak 97.

5. (2019) Oxford Research Encyclopedia. Available at: <http://linguistics. oxfordre.com/view/10.1093/acrefore/9780199384655.001.0001/acrefore9780199384655-e-43-> [Accessed August 2019].

6. Teterin, M. (2012) A Comparative Study of the Category of Gender in English and Romanian and Its Role in English Teaching/Learning. Available at: <http://dspace.usarb.md:8080/jspui/bitstream/123456789/26 97/1/teterin_a_comparative_study _conf_econom_2012.pdf> [Accessed September 2019].

7. Tiv'jaeva, I.V. Lekcii po teoreticheskoj grammatike anglijskogo jazyka. Available at: <http://window.edu.ru/catalog/pdf2txt/740/67740/41104> [Accessed August 2019].

8. Wikipedia, the Free Encyclopedia. Available at: <https://en.wikipedia.org/> [Accessed August 2019]. 


\section{Sources of Data:}

1. (1987) English Proverbs and Sayings. Yerevan: Luys.

2. Johnson, J.W. (2004) The Autobiography of an EX-Coloured Man, EBook\#11012. Available at: <http://library.umac.mo/ebooks/b280 458 77.pdf> [Accessed August 2019].

3. Rice, A. (1976) Interview with a Vampire. Vol. 1. Available at: <https://www.academia.edu/37488425> [Accessed August 2019].

\section{Utinh quinqh $2^{\text {nipq. }}$}

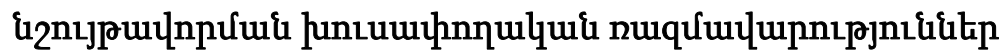

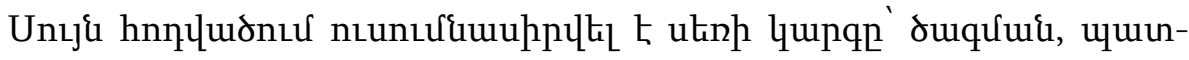

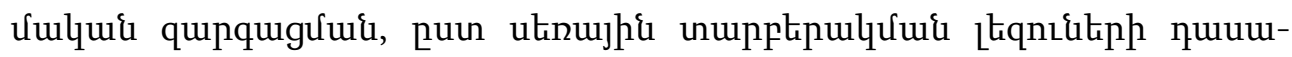

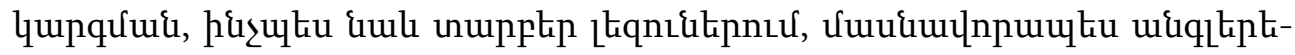

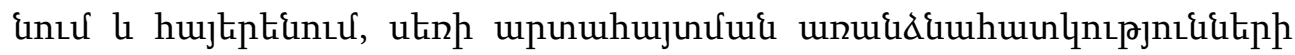

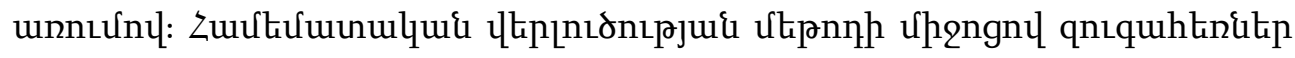

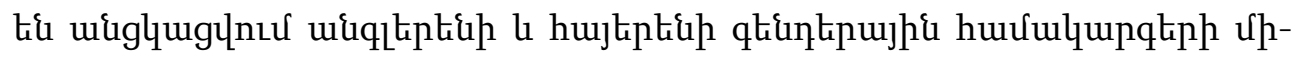

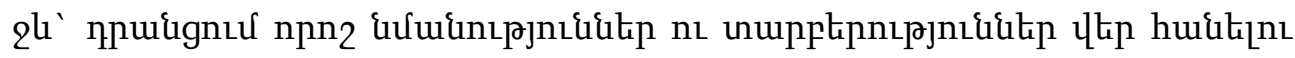

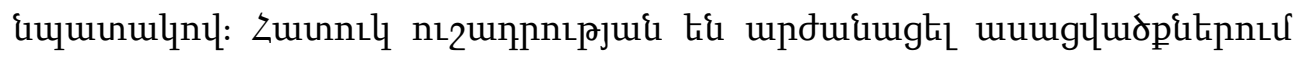

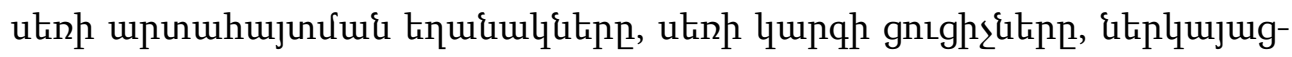

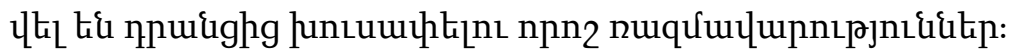

Received by the Editorial Board 10.09.2019

Recommended for publication by the reviewers 10.11.2019

Accepted for print 11.01.2020 